\title{
Periodontitis: A Risk Factor for Preterm Labour
}

\section{Shamila Ijaz Munir, ${ }^{1}$ Falak Naseer, ${ }^{2}$ Amna Ahsan, ${ }^{3}$ Mahnaz Gondal, ${ }^{4}$ Nazia Khalil, ${ }^{5}$ Nimra Rao $^{6}$}

\begin{abstract}
Objective: To determine the relationship between periodontitis and preterm labour in pregnant women presenting to a tertiary care hospital in Lahore.

Methods: This case control study was conducted at Obstetrics \& Gynecology Unit 4 of Sir Ganga Ram Hospital, Lahore for six months. The delivering women, who consented to participate, were divided into two case and control groups. For each case one control was enrolled who met the inclusion criteria, so total sample size was 380 women. Women delivered before 37 weeks of gestation were case group and those delivered after 37 weeks were control group. A patient was considered having periodontitis if she had probing pocket depth of $\geq 3 \mathrm{~mm}$ in at least 3 sites. Data was collected and analyzed on SPSS version 21 .

Results: In this study the mean age of the case group patients was $28.52 \pm 6.45$ years while of the control group was $28.67 \pm 6.35$ years. The mean value of probing depth pocket in the case group was $3.872 \pm 1.37$ while the mean value probing depth pocket of the control group was $3.58 \pm 1.52$. Out of 380 patients the periodontitis was found in 275 patients. The odds of having periodontitis in case group was 1.85 times higher than control group i.e. $\mathrm{OR}=1.85[1.17-2.92]$.

Conclusion: Periodontitis is a preventable risk factor of preterm labour in women presenting at a tertiary care hospital.

Keywords: Preterm Labour, Periodontitis, dental hygiene, preterm delivery
\end{abstract}

\section{Introduction}

$\mathrm{P}$ reterm delivery is also called as premature birth and it is delivery of a baby before 37 completed weeks of gestation. Preterm delivery is major cause of perinatal mortality and morbidity worldwide. About 15 million infants are born preterm (before 37 weeks of gestation) annually and they have low birth weight $(\mathrm{LBW}<2,500 \mathrm{~g})$. The incidence of Preterm delivery has been reported in the range from $5 \%$ to $7 \%$ of live births in some developed countries, but the same is much higher in developing countries. ${ }^{1}$ Premature infants are at greater risk of many mental and physical problems like cerebral palsy, delays in developmental

$\begin{array}{lll}\text { 1. Shamila Ijaz Munir } & 2 . & \text { Falak Naseer } \\ \text { 3. Amna Ahsan } & 4 . & \text { Mahnaz Gondal } \\ \text { 5. Nazia Khalil } & 6 . & \text { Nimra Rao } \\ \text { 1-6. Gynae Unit 4, Sir Ganga Ram } & \text { Hospital, Fatima Jinnah Medical } \\ \text { University, Lahore, Pakistan } & \\ \text { Correspondence: } & \\ \text { Prof Dr Shamila Ijaz Munir } & \\ \text { Head Gynae unit 4, Sir Ganga Ram Hospital, Fatima Jinnah Medical } \\ \text { University, Lahore, Pakistan } \\ \text { Email: shamilaijaz@yahoo.co.uk } \\ \text { Submission Date: } \\ \text { 1st Revision Date: } \\ \text { Acceptance Date: }\end{array}$

mile stones, hearing loss, poor digestion, weak immune system and perinatal mortality. Women with preterm infants also face many psychological and physical stresses. The prolonged hospital stay, multiple treatment interventions and fear of losing a baby may make them prone to postpartum depression. ${ }^{2}$ Since preterm delivery is a challenge in obstetrics therefore it is necessary to identify the risk factors. The exact cause of preterm labour is often not known but some of the risk factors include vaginal infections, diabetes, high blood pressure, multiple pregnancy, over or underweight, smoking and psychological stress. Among all the above said risk factors for preterm labour, maternal infection is the major one. ${ }^{3}$

Periodontal disease is caused mainly by gramnegative microaerophilic and anaerobic bacteria. They colonize the subgingival area and produce proinflammatory mediators like Prostaglandin E2, Tumour Necrosis Factor alpha (TNF- $\alpha$ ), Interleukin 1 beta (IL-1 $\beta$ ) and IL-6. These pro-inflammatory mediators have systemic effects on the host. ${ }^{4}$ Periodontal diseases are gingivitis and periodontitis. Gingivitis is gingival inflammation without loss of 
connective tissue attachment. Periodontitis is gingival inflammation at sites where there has been apical migration of the epithelial attachment on the root surfaces by the loss of connective tissue and alveolar bone. In the last twenty years many studies have shown the relationship between periodontitis and preterm labour. Periodontitis is a risk factor for preterm labour due to presence of bacteria and proinflammatory cytokines in blood that can affect the distant organs.

Rationale of this study is to determine the frequency and association of periodontitis with preterm labour in women presenting in a tertiary care hospital. In literature, the relationship of periodontitis with preterm labour is still not clear. Therefore, we conducted this study to get local evidence and implement the results of this study in local settings. Therefore, in future we can recommend the antenatal screening of pregnant women for periodontal diseases. ${ }^{7,8}$

\section{Objective}

To determine the relationship between periodontitis and preterm labour in pregnant women presenting to a tertiary care hospital in Lahore.

\section{Methods}

Study Design: Case control study

Setting: Obstetrics \& Gynecology Unit 4 ofSir Ganga Ram Hospital, Lahore

Duration: 6 months (8-5-2019 to 8-11-2019)

Sample Size: Sample size was 380 women. 190 women in control and the same number in case groups were calculated with $85 \%$ power of test with $5 \%$ level of significance and taking expected percentage of periodontitis i.e. $86 \%$ in case and $76 \%$ in control groups.

Sampling Technique: Non-probability, consecutive sampling

Inclusion Criteria: Women of age 18-40years, parity $<5$ presenting at gestational age $>28$ weeks (by first trimester scan) were included. Cases were those women in preterm labour ( $>3$ contractions in 10 minutes, Bishop score $>4$ and cervical dilation $>4 \mathrm{~cm}$ before completion of 37 weeks of gestation). Controls were those women in labour at term (gestational age $>37$ weeks).
Exclusion Criteria: Women with previous history of preterm labour, cervical incompetence, chronic or gestational hypertension, pre-eclampsia, eclampsia, diabetes, multiple pregnancy, abnormal placental implant (accrete, previa, increta) or placental abruption, amniotic fluid index $<5 \mathrm{~cm}$ or $>21 \mathrm{~cm}$ or women already taking treatment for periodontitis or other dental problems were excluded.

Data Collection Procedure: After taking informed consent, demographic profile was noted. Then women were divided into two groups i.e. cases in preterm labour and controls in term labour. After delivery the women were assessed for periodontitis by a single senior dentist having at least 4 years residency experience. Probing pocket depth was assessed and periodontitis was labeled according to WHO criterion for periodontitis i.e. probing pocket depth $\geq 4 \mathrm{~mm}$ in at least 3 sites, in different teeth. All this information was recorded on proforma. SPSS version 21 was used to enter and analyze the collected data. Odds ratio was calculated to measure association of periodontitis and preterm labour. OR $>1$ was considered as arisk of preterm labour.

\section{Results}

The mean age of the cases group patients was $28.52 \pm 6.45$ years while the mean age of the control group was $28.67 \pm 6.35$ years. The mean gestational age of the cases group patients was $34.48 \pm 1.74$ weeks while in control group was $38.92 \pm 0.79$ weeks. There were $65(17.11 \%)$ nulliparous women, 62(16.32\%) had one child, $115(30.26 \%)$ had two children, $85(22.37 \%)$ had three children and 53(13.95\%) women had four children. The mean BMI of the cases group patients was $24.84 \pm 5.054 \mathrm{~kg} / \mathrm{m}^{2}$ while in control group was $26.50 \pm 5.45 \mathrm{~kg} / \mathrm{m}^{2}$. This difference was statistically significant i.e. p-value $=0.002$. According to this study the mean probing pocket depth of periodontitis in the cases group was $3.872 \pm$ 1.37 while in control group was $3.58 \pm 1.52$. This difference was statistically significant i.e. $p$-value= 0.050. (Table-1). The results of this study show that out of 380 patients the periodontitis was found in 275(72.37\%) patients (Fig-1). In cases group the periodontitis was found in $149(78.4 \%)$ respondents while in control group the periodontitis was found in $126(66.3 \%)$ respondents. The odds of having periodontitis in cases group is 1.85 time higher than control group i.e. $\mathrm{OR}=1.85[1.17-2.92]$. $($ Table-2) 
Table 1: Demographic Features of Patients

\begin{tabular}{lcc}
\hline & \multicolumn{2}{c}{ Study Groups } \\
\cline { 2 - 3 } \multicolumn{1}{c}{$\mathbf{n}$} & Case & Control \\
\cline { 2 - 3 } \multicolumn{1}{c}{} & $\mathbf{1 9 0}$ & $\mathbf{1 9 0}$ \\
\hline Age (Years) & $28.52 \pm 6.45$ & $28.67 \pm 6.35$ \\
Gestational age (weeks) & $34.48 \pm 1.74$ & $38.92 \pm 0.79$ \\
BMI $\left(\mathrm{Kg} / \mathrm{m}^{2}\right)$ & $24.84 \pm 5.05$ & $26.50 \pm 5.45$ \\
Probing depth & $3.87 \pm 1.37$ & $3.58 \pm 1.52$ \\
Primiparous & 61 & 66 \\
Multiparous & 129 & 124 \\
\hline
\end{tabular}

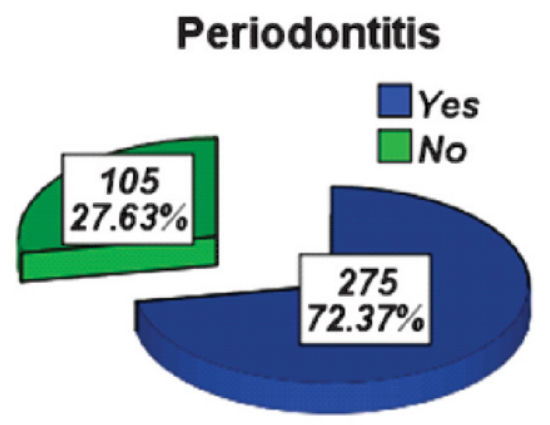

Figure-1: Distribution of Periodontitis

Among patients with age $\leq 30$ years the odds of having periodontitis is 2.28 time higher in cases group than control groups i.e. $\mathrm{OR}=2.28[1.22-4.26]$. Among patients with gestational age $>36$ weeks there is insignificant difference found between the study groups with periodontitis i.e. $\mathrm{p}$-value $=0.068$. Among

Table 2: Association of Periodontitis with Preterm Labour

\begin{tabular}{rccccc}
\hline & & \multicolumn{2}{c}{ Study Groups } & \multirow{2}{*}{ Total } & OR [95\% \\
\cline { 2 - 4 } & & Case & Control & & CI] \\
\hline & Yes & 149 & 126 & 275 & \\
Periodontitis & & $78.4 \%$ & $66.3 \%$ & $72.4 \%$ & \\
& No & 41 & 64 & 105 & $\mathbf{1 . 8 5}$ \\
& & $21.6 \%$ & $33.7 \%$ & $27.6 \%$ & {$[\mathbf{1 . 1 7 - 2 . 9 2}]$} \\
Total & & 190 & 190 & 380 & \\
& & $100 \%$ & $100 \%$ & $100 \%$ & \\
\hline
\end{tabular}

multi-parity patients the odds of having periodontitis is 2.23 time higher in cases group than control groups i.e. $\mathrm{OR}=2.23[1.27-3.89]$. Among patients with overweight \& obese BMI status the odds of having periodontitis is 2.19 time higher in cases group than control groups i.e. $\mathrm{OR}=2.19[1.12-4.28]$. (Table-3)

\section{Discussion}

In this study cases and controls were recruited with intent to conduct a case-controlstudy with cases being mothers who experienced preterm labor and controls being mothers without preterm labour and having infants weighing more than 2500 grams. These cases and controls came from same pool of patients delivering in Sir Ganga Ram Hospital Lahore in Gynae Unit 4. Counseling was done and informed consent was taken during early labour so all cases could be enrolled with a comparable number of controls. The advantage of the study is that all

Table 3: Association of Periodontitis with Preterm Labour Stratified by Effect Modifiers

\begin{tabular}{|c|c|c|c|c|c|}
\hline \multirow{2}{*}{ Age (Years) } & \multirow{2}{*}{$\begin{array}{l}\text { Period } \\
\text { on titis }\end{array}$} & \multicolumn{2}{|c|}{ Study Groups } & \multirow{2}{*}{ Total } & \multirow{2}{*}{$\begin{array}{l}\text { OR }(95 \% \\
\text { CI) }\end{array}$} \\
\hline & & Case & Control & & \\
\hline \multirow{4}{*}{$\leq \mathbf{3 0}$} & Yes & 95 & 75 & 170 & \multirow{4}{*}{$\begin{array}{c}2.28 \\
{[1.22-4.26]}\end{array}$} \\
\hline & \multirow{3}{*}{ No } & $82.6 \%$ & $67.6 \%$ & $75.2 \%$ & \\
\hline & & 20 & 36 & 56 & \\
\hline & & $17.4 \%$ & $32.4 \%$ & $24.8 \%$ & \\
\hline \multirow{4}{*}{$>\mathbf{3 0}$} & Yes & 54 & 51 & 105 & \multirow{4}{*}{$\begin{array}{c}1.41 \\
{[0.71-2.79]}\end{array}$} \\
\hline & & $72.0 \%$ & $64.6 \%$ & $68.2 \%$ & \\
\hline & No & 21 & 28 & 49 & \\
\hline & & $28.0 \%$ & $35.4 \%$ & $31.8 \%$ & \\
\hline \multirow{4}{*}{$\begin{array}{l}\text { Gestational } \\
\text { age } 32-36 \\
\text { weeks }\end{array}$} & Yes & 132 & 0 & 132 & \multirow{4}{*}{--} \\
\hline & & $84.6 \%$ & $0 \%$ & $84.6 \%$ & \\
\hline & No & 24 & 0 & 24 & \\
\hline & & $15.4 \%$ & $0 \%$ & $15.4 \%$ & \\
\hline \multirow{4}{*}{$\begin{array}{c}\text { Gestational } \\
\text { age }>36 \\
\text { weeks }\end{array}$} & Yes & 17 & 126 & 143 & \multirow{4}{*}{$\begin{array}{c}0.51 \\
{[0.24-1.061]}\end{array}$} \\
\hline & & $50.0 \%$ & $66.3 \%$ & $63.8 \%$ & \\
\hline & No & 17 & 64 & 81 & \\
\hline & & $50.0 \%$ & $33.7 \%$ & $36.2 \%$ & \\
\hline \multirow{4}{*}{ Primiparous } & Yes & 47 & 48 & 95 & \multirow{4}{*}{$\begin{array}{c}1.25 \\
{[0.56-2.82]}\end{array}$} \\
\hline & & $77.0 \%$ & $72.7 \%$ & $74.8 \%$ & \\
\hline & No & 14 & 18 & 32 & \\
\hline & & $23.0 \%$ & $27.3 \%$ & $25.2 \%$ & \\
\hline \multirow{4}{*}{ Multiparous } & Yes & 102 & 78 & 180 & \multirow{4}{*}{$\begin{array}{c}2.23 \\
{[1.27-3.89]}\end{array}$} \\
\hline & & $79.1 \%$ & $62.9 \%$ & $71.1 \%$ & \\
\hline & No & 27 & 46 & 73 & \\
\hline & & $20.9 \%$ & $37.1 \%$ & $28.9 \%$ & \\
\hline \multirow{4}{*}{ ВМI $<24.9$} & Yes & 74 & 49 & 123 & \multirow{4}{*}{$\begin{array}{c}1.69 \\
{[0.88-3.24]}\end{array}$} \\
\hline & & $74.7 \%$ & $63.6 \%$ & $69.9 \%$ & \\
\hline & No & 25 & 28 & 53 & \\
\hline & & $25.3 \%$ & $36.4 \%$ & $30.1 \%$ & \\
\hline \multirow{4}{*}{ BMI $>24.9$} & Yes & 75 & 77 & 152 & \multirow{4}{*}{$\begin{array}{c}2.19 \\
{[1.12-4.28]}\end{array}$} \\
\hline & & $82.4 \%$ & $68.1 \%$ & $74.5 \%$ & \\
\hline & No & 16 & 36 & 52 & \\
\hline & & $17.6 \%$ & $31.9 \%$ & $25.5 \%$ & \\
\hline
\end{tabular}

periodontal examination was done in a standardized way by trained medical practitioners.

In our study the mean age of the cases group patients was $28.52 \pm 6.45$ years which was not significantly different from controls $28.67 \pm 6.35$ years. This result is similar to other study having the mean age for case $25 \pm 6.3$ (SD) years, while the mean age of the control group was $22 \pm 3.4$ years. ${ }^{9}$ There was no significant 
difference among the parity between cases and controls, and the mean gestational age of preterm labour was 34 weeks which is similar to other studies. ${ }^{10}$ High or low BMI was not significantly associated with preterm birth and was same in both cases and control groups. ${ }^{11}$

In current study out of 380 patients the periodontitis was found in $275(72.37 \%)$ patients in total. In the cases group the periodontitis was found in $149(78.4 \%)$ participants and in control group the periodontitis was found in $126(66.3 \%)$ participants. According to this study the odds of having periodontitis in case group is 1.85 time higher than control group i.e. $\mathrm{OR}=1.85[1.17-2.92]$. The results of this study are similar to the results of a study conducted by Chokkaiyan et al. ${ }^{12}$ in which periodontitis among cases was $86 \%$ and among controls it was $75 \%$. Although the reported difference was significant ( $\mathrm{P}=0.001)$ yet the frequency of periodontitis is not negligible in control group.

The study conducted by Offenbacher et al. ${ }^{13}$ reported a link between poor maternal periodontal health and preterm delivery. As per the said study pregnant women with periodontitis have 7.5 times more risk of developing preterm labour as compared to controls. This result is higher than our study result.

Another study published in $2018^{14}$ showed that the mothers in the periodontitis group delivered preterm infants at eight-fold higher frequency and low birth weight infants with ten-fold higher frequency as compared to control group. The studies conducted in USA show significant relationship between periodontal disease and preterm delivery among AfricanAmerican racial/ethnic groups and those women who smoke during pregnancy. ${ }^{15,16}$ Another study by Jeffcoat et $\mathrm{al}^{17}$ demonstrated that there is beneficial effect on preterm labour if periodontal treatment is successful. As per logistic regression analysis there is significant relationship between successful periodontal treatment and full-term birth (adjusted odds ratio 6.02; 95\% CI 2.57-14.03). The subjects, refractory to periodontal treatment were significantly at higher risk to have preterm labour.

On the other hand, a study by Lohsoonthorn et $\mathrm{al}^{18}$ on Thai women does not provide enough evidence that periodontal disease is associated with preterm labour.
Lohsoonthorn et al. reported that among cases $25.3 \%$ women had periodontitis while among controls $22.7 \%$ women had periodontitis. The reported difference was insignificant $(\mathrm{P}>0.05)$, thus showing a nonsignificant relationship between periodontitis and preterm labour.

Two studies conducted in the United Kingdom have failed to determine significant relationship between periodontal disease in pregnancy and risk of preterm delivery. ${ }^{1920}$ In addition, Martinez-Martinez et al. ${ }^{21}$ suggested that Preterm birth is because of many other reasons therefore periodontal pathogens are not sufficient to cause Preterm birth.

There are many cohort studies reported in literature showing an association among periodontitis and preterm birth, low birth weight or preterm pre-labour rupture of membranes. In 2016, a hospital-based prospective study on 790 pregnant women found that periodontitis was a risk factor for preterm birth and low birth weight. ${ }^{22}$ Recently periodontitis was also found to be associated with pre-eclampsia and PROM as common causes of preterm birth. ${ }^{23}$

A meta-analysis done by Vivares-Builes ${ }^{24}$ reviewed 99 observational studies. Most of them have highlighted association among maternal periodontitis and a higher risk of low birth weight, preterm delivery and pre-eclampsia.

There is a need of more multicenter studies to be conducted to reach a definite association between periodontitis and preterm labour. For the time being, routine ante-natal dental evaluation can be practiced and patients having periodontitis should be treated to prevent preterm labour.

\section{Conclusion}

Our study has concluded that periodontitis is associated with preterm labour in women who presented at a tertiary care hospital of Lahore, Pakistan.

\section{Author's Contribution}

SIM: Original Idea, Conception of work

FN: Paper writing

AA: Designed Analysis

MG, NR: Data Collection

NK: Analytical interpretation of results 


\section{References}

1. Beck S, Wojdyla D, Say L, Betran AP, Merialdi M, Requejo $\mathrm{JH}$, et al. The worldwide incidence of preterm birth: a systematic review of maternal mortality and morbidity. Bulletin of the World Health Organization 2010;88(1):31-8.

2. Omar AE. Physiological, Psychosocial, Behavioral, Socio-demographic Risk Factors and Antepartum Bed Rest Associated with Gestational Age at Birth and Postpartum Depression in High Risk Pregnant Women: Case Western Reserve University; 2013.

3. Kruse, A.B., Kuerschner, A.C., Kunze, M. et al. Association between high risk for preterm birth and changes in gingiva parameters during pregnancy-a prospective cohort study. Clin Oral Invest 2018;22: 1263-1271

4. Khadem N, Rahmani ME, Sanaei A, Afiat M. Association between preterm and low-birth weight with periodontal disease: a case-control study. Iranian journal of reproductive medicine 2012; 10(6): 561.

5. Murphey C. Oral health experiences of pregnant and parenting adolescent women: a qualitative descriptive study. International journal of nursing studies 2013; 50(6):768-75.

6. Haerian-Ardakani A, Eslami Z, Rashidi-Meibodi F, Haerian A, Dallalnejad P, Shekari M, et al. Relationship between maternal periodontal disease and low birth weight babies. Iran J Reprod Med 2013; 11(8): 625-30.

7. Ren H, Du M. Role of Maternal Periodontitis in Preterm Birth. Frontiers in Immunology 2017;8:62832

8. Graves D. Cytokines that promote periodontal tissue destruction. Journal of periodontology 2008;79: 1585-91.

9. Karimi MR, Hamissi JH, Naeini SR, Karimi M. The relationship between maternal periodontal status and preterm and low birth weight infants in Iran: a case control study. Global journal of health science 2016; 8(5): 184 .

10. Harper LM, Parry S, Stamilio DM, Odibo AO, Cahill AG, Strauss III JF, et al. The interaction effect of bacterial vaginosis and periodontal disease on the risk of preterm delivery. American journal of perinatology 2012;29(05):347-52.

11. Govindasamy R, Dhanasekaran M, Varghese SS, Balaji VR, Karthikeyan B, Christopher A. Maternal Risk Factors and Periodontal Disease: A Crosssectional Study among Postpartum Mothers in Tamil Nadu. J Pharm Bioallied Sci. 2017;9(Suppl 1): S50-
S54.

12. Chokkaiyan S, Arumugam SC, Kumar S, John LB, Ghose S. Periodontitis as a risk factor for preterm labour and low birth weight among pregnant women attending a tertiary care teaching hospital. International Journal of Reproduction, Contraception, Obstetrics and Gynecology 2015;4(6):1804-10

13. Offenbacher S, Katz V, Fertik G, Collins J, Boyd D, Maynor G, et al. Periodontal infection as a possible risk factor for preterm low birth weight. Journal of periodontology 1996;67:1103-13.

14. Fogacci MF, Cardoso EdC, Barbirato Dd et al. No association between periodontitis and preterm low birth weight: a case-control study. Arch Gynecol Obstet 2018;297, 71-76.

15. Lunardelli AN, Peres MA. Is there an association between periodontal disease, prematurity and low birth weight? A population-based study. Journal of Clinical Periodontology 2005;32(9):938-46.

16. Mannem S, Chava VK. The relationship between maternal periodontitis and preterm low birth weight: A case-control study. Contemporary clinical dentistry 2011;2(2):88.

17. Jeffcoat M, Parry S, Sammel M, Clothier B, Catlin A, Macones G. Periodontal infection and preterm birth: successful periodontal therapy reduces the risk of preterm birth. BJOG: An International Journal of Obstetrics \& Gynaecology 2011;118(2):250-6.

18. Lohsoonthorn V, Kungsadalpipob K, Chanchareonsook $\mathrm{P}$, Limpongsanurak S, Vanichjakvong $\mathrm{O}$, Sutdhibhisal S, et al. Is maternal periodontal disease a risk factor for preterm delivery? American journal of epidemiology 2009;169(6):731-9

19. Moore S, Ide M, Coward P, Randhawa M, Borkowska E, Baylis R, et al. A prospective study to investigate the relationship between periodontal disease and adverse pregnancy outcome. British dental journal 2004;197(5):251.

20. Bhattacharya S, Raja EA, Mirazo ER, Campbell DM, Lee AJ, Norman JE, et al. Inherited predisposition to spontaneous preterm delivery. Obstetrics \& Gynecology 2010;115(6):1125-33.

21. Martínez-Martínez RE, Moreno-Castillo DF, Loyola-Rodríguez JP, Sánchez-Medrano AG, San Miguel-Hernández JH, Olvera-Delgado JH, et al. Association between periodontitis, period on to pathogens and preterm birth: is it real? Archives of gynecology and obstetrics 2016;294(1):47-54.

22. Perunovic ND, Rakic MM, Nikolic LI, Jankovic SM, Aleksic ZM, Plecas DV, et al. The association between periodontal inflammation and labor triggers 
(elevated cytokine levels) in preterm birth: A crosssectional study. Journal of periodontology 2016; 87(3): 248-256.

23. Puertas A, Magan-Fernandez A, Blanc V, et al. Association of periodontitis with preterm birth and low birth weight: a comprehensive review, The Journal of Maternal-Fetal \& Neonatal Medicine,
2018;31(5):597-602

24. AM Vivares-Builes, LJ Rangel-Rincón, JE Botero at el.Gaps in knowledge about the association between maternal periodontitis and adverse obstetric outcomes: an umbrella reviewJournal of EvidenceBased Dental Practice 2018;18(1):1-27 